\title{
A Compact UWB Microstrip Antenna With Hexagonal Circular Patch And Asymmetric CPW-Fed for On-body Applications
}

\author{
Lakshmi Charan Tangisetti ${ }^{1}$, T.V. Rama Krishna ${ }^{2}$, K. Kumar Naik ${ }^{3}$ \\ ${ }^{1}$ Department of ECE, KLEF, Vaddeswaram, Guntur, India, charantangisetti@gmail.com \\ ${ }^{2}$ Department of ECE, KLEF, Vaddeswaram, Guntur, India, tottempudi@kluniversity.in \\ ${ }^{3}$ Department of ECE, KLEF, Vaddeswaram, Guntur, India, kumarnaik@kluniversity.in
}

\begin{abstract}
A compact UWB microstrip antenna with hexagonal circular patch (CHCP) and asymmetric coplanar waveguide (cpw-fed) is presented. A complimentary split ring resonator (CSRR) is embedded on hexagonal circular patch and also four slits are loaded on the patch to obtain ultra-wideband. The proposed CHCP microstrip antenna is operating over frequency range of $3.2 \mathrm{GHz}$ to $10.6 \mathrm{GHz}$, with the impedance bandwidth of 7.4GHz. The hexagonal circular patch antenna was resonating at three frequencies $4.1 \mathrm{GHz}, 7.2 \mathrm{GHz}, 10.42 \mathrm{GHz}$ respectively. The parametric analysis is also studied.
\end{abstract}

Key words: Hexagonal Circular Patch, CPW-Fed, ultra-wide band, impedance bandwidth.

\section{INTRODUCTION}

The (FCC) federal communication commission has allocated frequency spectrum over $3.1 \mathrm{GHz}$ to $10.6 \mathrm{GHz}$ with the impedance bandwidth of $7.2 \mathrm{GHz}$ for unlicensed ultra-wideband measurements. Now a day's ultra-wideband antennas have attracted attention because of simple structure, low profile, ease of integration, fabrication.

The ultra-wideband (UWB) is considerd for on-body applications because [1] it offers a low radiation power with a high data rate. A double layered bow tie antenna [2] is proposed with a miniaturization technique in order to increase the electrical length of antenna with a coaxial feeding method. A compact ultra-wide-band microstrip antenna [3] is designed for wireless body area networks applications shown a low SAR and a truncated structure to be suitable for on-body applications and dimensions of proposed antenna is $25 \mathrm{X} 22 \mathrm{X}$ $10 \mathrm{~mm}^{3}$ with the ground plane of $50 \times 50 \mathrm{~mm}^{2}$ is considered and the antenna is operating at $6 \mathrm{GHz}$. A compact monopole [4].

UWB antenna is simulated and tested on a human hand model and vixen phantom for on-body communications. The results were compared, and a two-thirds muscle phantom is considered. The dimensions of proposed antenna are $25 \times 10 \times 1.6 \mathrm{~mm}$ and antenna has operated at $7 \mathrm{GHz}$ with reflection coefficient of $-30 \mathrm{~dB}$ and microstrip antenna has resonated at single operating frequency, Different types of radiation patterns are analyzed for omnidirectional, directional, and pattern diversity radiation characteristics of UWB antennas [5] by placing them on the body. A flexible substrate antenna [6] using a polyimide substrate is presented to obtain dual-band operation for wireless local network application. Effect of ultra wide Band antenna on the human head is determined by using a numerical model [7].

This is shown to obtain increase gain and radiation characteristics of microstrip antenna. A multiple number of homogeneous head phantom models [8] are considered for analyzing the electromagnetic energy absorption due to UWB models for on body wearable antennas. An on-body channel for UWB has proposed [9] with a channel modelling for transmitter and receiver, and the FDTD method is used for obtaining the numerical analysis. The millimetre waves interaction with the human body, reported in the study [10], with most advanced techniques over very high frequency for different scientific approaches such as on body and off-body and concluded, as dielectric constant of the human body is proportional to the changes with the frequency of operation, such study is helpful to design a on-body antenna. Body-area networks (BAN) are used in between on-body and implantable devices which are widely used for medical applications [11].

The coplanar waveguide fed microstrip antenna, which is similar for a microstrip aperture-coupled antenna, electromagnetic energy will be coupled from feeding line to the radiating patch through coupling slot and this cpw feeding improves gain over a wideband [12]. A CPW-Fed microstrip antenna makes an easier integration between active devices [13] - [15]. It also allows realization between series and shunt connections on one side of dielectric substrate along with ground plane. It allows integration of lumped elements with active devices very easily. Therefore, using coplanar wave guide to feed a patch has the advantage of less loss at high frequencies. 
A coplanar waveguide fed microstrip antenna is implemented for triple band WLAN application [16]. A compact CPW fed antenna [17] for WiMAX applications along with broad band tuning ability is presented in [18]. A microstrip antenna with split ring resonator for ultra-wideband is presented in this two pairs of split ring resonator called a metamaterial structure and which are closely spaced from feed to obtain good impedance matching over complete band. Now, CSRR along with SRR are the dual elements and operating frequency remains same for some dimensions. CSRR is formed while engraving copper material and ground plane. The ideal circuit of SRR and CSRR consist of parallel LC circuit [19] and this is mainly used for gain enhancement and size reduction [20][22].

In this paper, the hexagonal patch antenna is manufactured on flexible material, the proposed antenna operates in ultra-wideband for on-body applications, and the monopole is in shape of a hexagon with a compact size of $(20 \mathrm{X} 18 \mathrm{X} 0.08$ $\mathrm{mm}^{3}$ ) is operating $3.2 \mathrm{GHz}-10.6 \mathrm{GHz}$ frequency band.

\section{ANTENNA DESIGN}

\subsection{Design process of CHCP Antenna.}

The kapton polyamide flexible substrate material is considered with $\left(\varepsilon_{\mathrm{r}}\right) 4.3$ and loss tangent $(\delta) 0.004$. Below, a hexagonal shaped patch is considered, the substrate height is $0.08 \mathrm{~mm}$. A hexagonal shaped CSRR is considered and etched from the center of radiating patch with slot width of $\mathrm{W}_{6}$, four parallel rectangular slits with Length $\mathrm{L}_{3}$ and Width $\mathrm{W}_{5}$ are etched on radiating patch as represented in Figure 1.

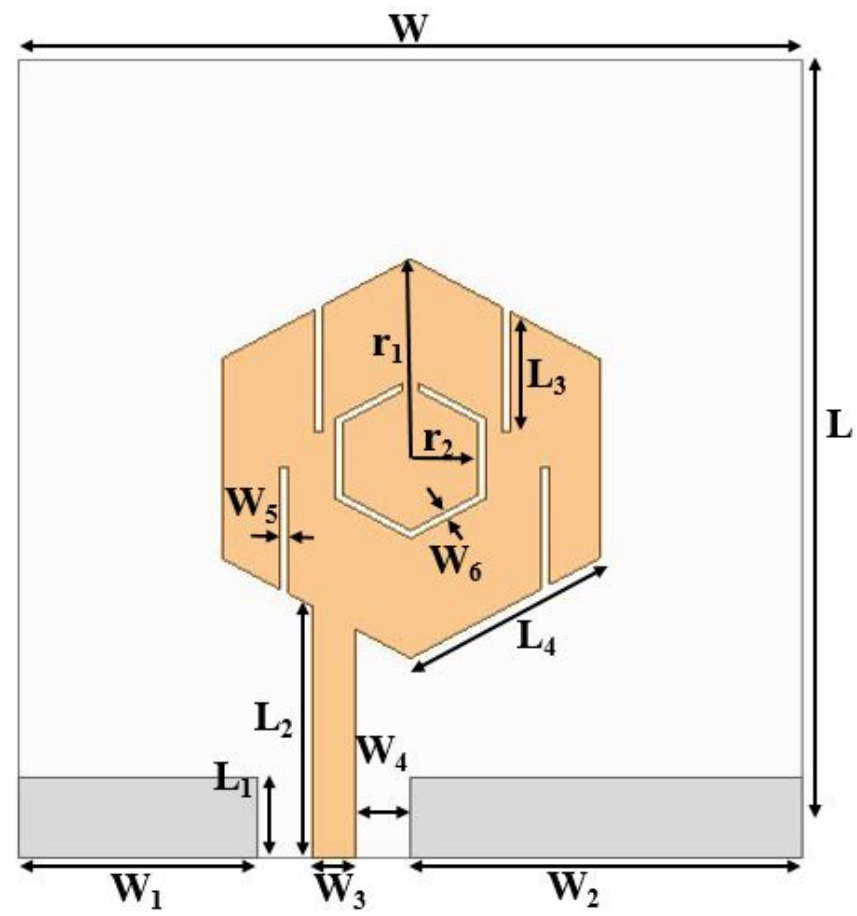

Figure 1: Proposed microstrip dual hexagon antenna (CHCP)
An asymmetric cpw fed is considered with two asymmetrical which is place in between ground planes with input

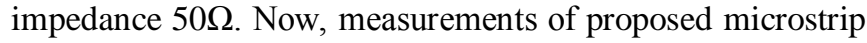
CHCP antenna model is represented in Table 1. The CSRR width was considered as $0.2 \mathrm{~mm}$.

To obtain the UWB band the optimization is analyzed with HFSS tool. The resonant frequency of hexagon patch is given with the following equation

$f_{r}=\frac{8.794}{r_{e} \sqrt{\varepsilon_{r}}}$

Where $r_{e}$ is

$r_{e}=r_{1}\left[1+\frac{2 h}{\prod_{1} \varepsilon_{r}}\left\{\ln \left(\frac{r_{1}}{2 h}\right)+\left(1.4 \varepsilon_{r}+1.768\right)+\frac{h}{r_{1}}\left(0.267 \varepsilon_{r}+1.649\right)\right\}\right]^{-1 / 2}$

Substrate is metallized with dual hexagonal patch and the length of each side can be calculated by the following equation

$L_{4}=2 r_{1} \sin \left(\frac{\pi}{n}\right)$

$\mathrm{n}=$ number of sides; $\mathrm{r}_{1}=$ =radius

Above, Figure 1 exhibits compact microstrip antenna with CPW-Fed and hexagonal circular patch with step by step evolution process as shown in Figure 2. During initial design, a hexagon with a full ground is considered. The antenna in the first step (Ant 1) has a very high reflection coefficient, directional pattern of antenna which is very poor. As the antenna is intended for UWB application, the evolution process was presented for understanding resonating of antenna at particular desired frequency. In second step (Ant 2) taken in the evolution process is to consider a CPW feeding method by removing the full ground making the resonating patch and ground lie in the one plane. In this step, the antenna is resonating at $4.9 \mathrm{GHz}$ having reflection coefficient $-30.45 \mathrm{~dB}$ and bandwidth is $4320 \mathrm{MHz}$ as observed.

Table 1: Antenna Parameters

\begin{tabular}{|c|c|c|c|}
\hline Parameter & Value(mm) & Parameter & Value $(\mathbf{m m})$ \\
\hline $\mathrm{W}$ & 18 & $\mathrm{~L}_{3}$ & 3.25 \\
\hline $\mathrm{L}$ & 20 & $\mathrm{~W}_{4}$ & 1.25 \\
\hline $\mathrm{W}_{1}$ & 5.5 & $\mathrm{~W}_{5}$ & 0.2 \\
\hline $\mathrm{L}_{1}$ & 2 & $\mathrm{~W}_{6}$ & 0.1 \\
\hline $\mathrm{W}_{2}$ & 9 & $\mathrm{r}_{1}$ & 5 \\
\hline $\mathrm{L}_{2}$ & 7.5 & $\mathrm{r}_{2}$ & 2 \\
\hline $\mathrm{W}_{3}$ & 1 & $\mathrm{~L}_{4}$ & 4.33 \\
\hline
\end{tabular}

In the further evolution process (Ant 3), slits were added in to the hexagon and its parameters in Figure 2. In this step, the antenna is resonated at $2.89 \mathrm{GHz}, 5.24 \mathrm{GHz}$, and $6.15 \mathrm{GHz}$ and impedance bandwidths of $940 \mathrm{MHz}, 1940 \mathrm{MHz}$, and 1940 $\mathrm{MHz}$ is observed for respective frequency. At fourth step (Ant 4) Complimentary split ring resonator is considered at center with a $2 \mathrm{~mm}$ radius. The proposed antenna is resonating at $4.1 \mathrm{GHz}, \quad 7.2 \mathrm{GHz}$, and $10.42 \mathrm{GHz}$ with the reflection coefficients of $-21.42 \mathrm{~dB}, \quad-34.01 \mathrm{~dB}$, and $-11.96 \mathrm{~dB}$ respectively. 
Figure 3 represents the reflection coefficient plot for the evolution process of chcp antenna. The optimized parameters are listed in Table 2.

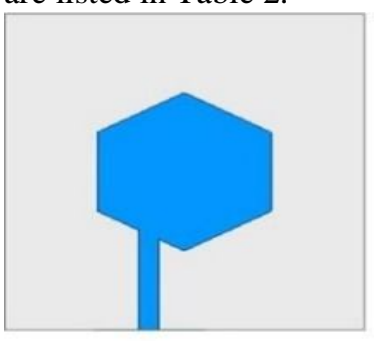

(a)

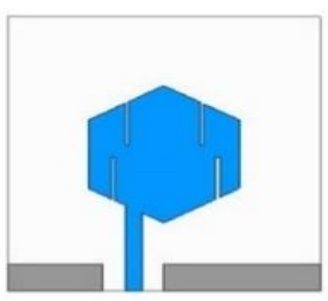

(c)

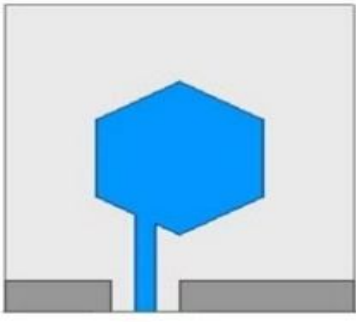

(b)

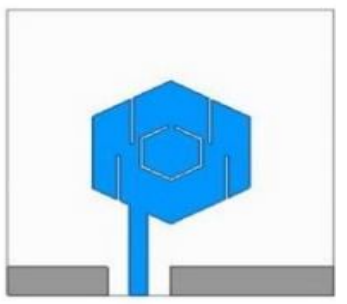

(d)
Figure 2: Proposed CHCP antenna evolution.

Table 2: Evolution process of CHCP antenna

\begin{tabular}{|c|c|c|c|c|}
\hline S. & $\begin{array}{c}\text { Evolution } \\
\text { process } \\
\text { antenna }\end{array}$ & $\begin{array}{c}\text { Operating } \\
\text { Frequency }\end{array}$ & $\begin{array}{c}\text { Reflection } \\
\text { Coefficient }\end{array}$ & Bandwidth \\
\hline 1 & ANT 1 & 10.56 & -5.27 & - \\
\hline 2 & ANT2 & 4.9 & -30.45 & 4320 \\
\hline \multirow{2}{*}{3} & \multirow{2}{*}{ ANT3 } & 1.81 & -19.42 & 430 \\
\cline { 3 - 5 } & & 7.26 & -14.2 & 750 \\
\hline \multirow{2}{*}{4} & \multirow{2}{*}{ ANT4 } & 4.1 & -21.42 & 6090 \\
\cline { 3 - 5 } & & 7.2 & -34.01 & 6090 \\
\cline { 3 - 5 } & & 10.42 & -11.96 & 820 \\
\hline
\end{tabular}

The evolution of the antenna taken four steps to reach to the tabulated and is shown in Table 2. The reflection coefficient for the evolution design was presented in Figure 3.

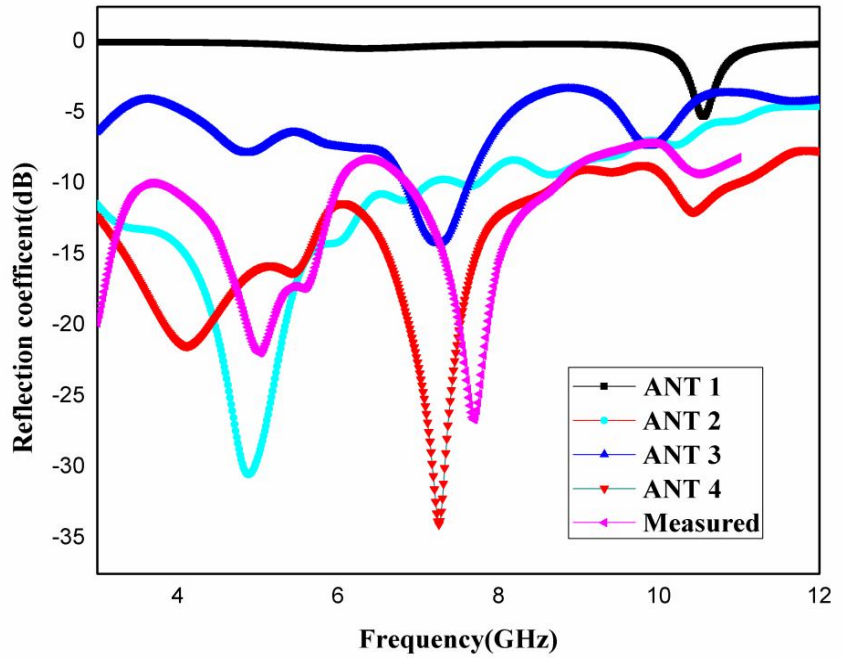

Figure 3: Reflection coefficient comparison of the evolution process.
The Ant 2 and Ant 4 gave better results for the required UWB application. The Ant 2 is operating dual-band and Ant 4 is operating at three resonant frequencies.

\subsection{Parametric Analysis}

In the process of optimization, to enhance the parameters of the antenna, a parametric set has been considered the width of the CSRR is varied to obtain a better reflection coefficient.

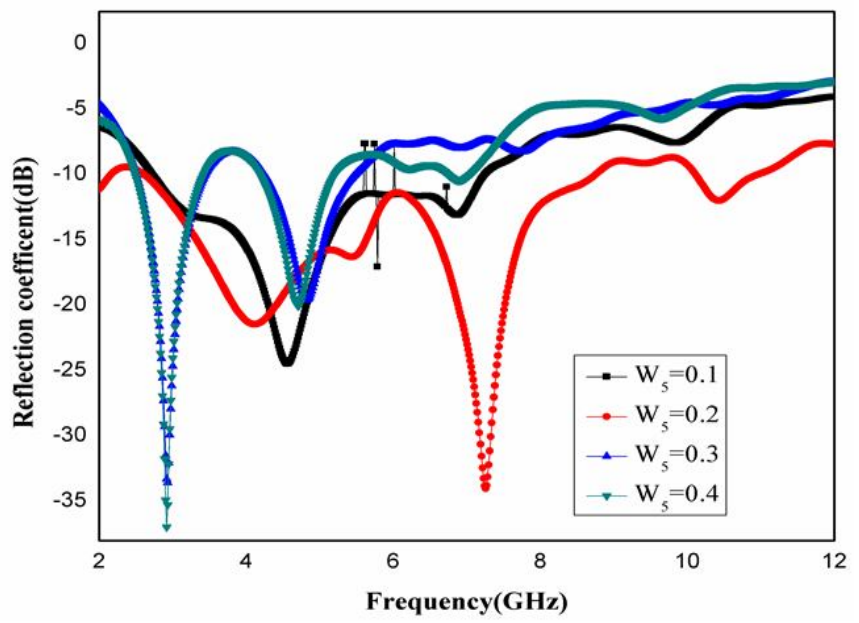

Figure 4: The parametric sweep of $\mathrm{CHCP}$ antenna for $\mathrm{W}_{5}$

The parametric analysis for the PEPA is done to get better understanding of the antenna. Two parameters are considered which might enhance the operation of the antenna to broadband. The parameters $\mathrm{W}_{5}$ and $\mathrm{W}_{6}$ are considered for Optimization of the results. The Opti metric analysis is done using FEM. Figure 4 represents the Opti metric analysis for parameter $\mathrm{W}_{5}$, width of the slits. The values range from $0.1 \mathrm{~mm}$ to $0.4 \mathrm{~mm}$. The better result is observed when $\mathrm{W}_{5}$ is $0.2 \mathrm{~mm}$.

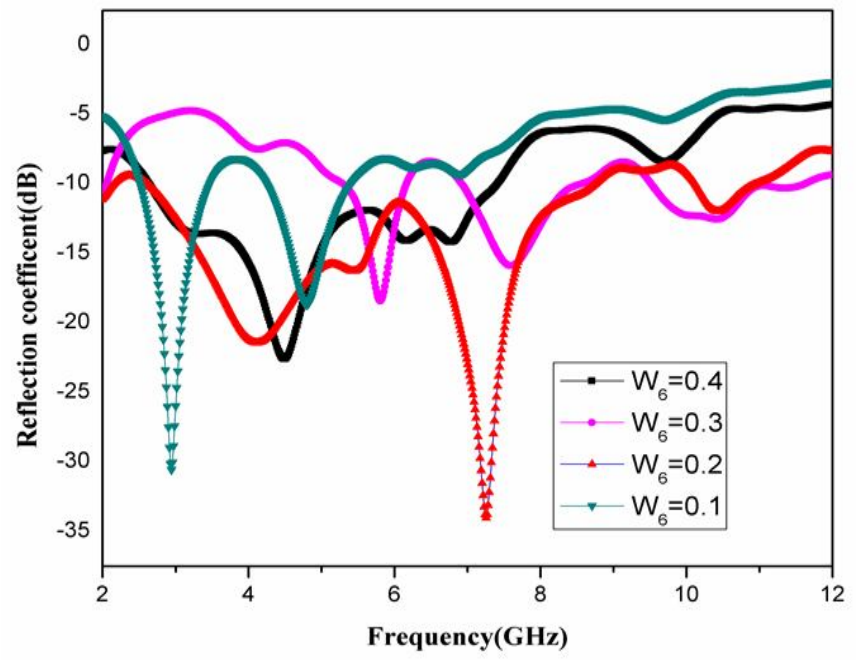

Figure 5: The parametric sweep of $\mathrm{CHCP}$ antenna for $\mathrm{W}_{6}$

The second parameter considered for the Opti metric is $\mathrm{W}_{6}$, width of the CSRR. The CSRR is considered to increase the current path. The width will be varying from $0.1 \mathrm{~mm}$ to 
$0.4 \mathrm{~mm}$. The antenna gave three resonances for the $0.2 \mathrm{~mm}$ width and the best result in the considered width range. The Figure 5 represents the reflection coefficient for the Opti-metric analysis of $\mathrm{W}_{6}$.

Table 3, Table 4 shows reflection coefficient values for the Opti metric analysis of $\mathrm{W}_{5}$ and $\mathrm{W}_{6}$. Each of the parameter is varied for four steps and plotted the reflection coefficient comparison.

Table 3: Evolution process of CHCP antenna with $\mathrm{W}_{5}$

\begin{tabular}{|c|c|c|}
\hline S.no & $\mathbf{W}_{\mathbf{5}}$ & Reflection coefficient(dB) \\
\hline 1 & 0.1 & $-24.55,-13.01,-13.07$ \\
\hline 2 & 0.2 & $-21.42,-34.01,-11.96$ \\
\hline 3 & 0.3 & $-33.56,-19.58$ \\
\hline 4 & 0.4 & $-36.95,-20.01,-10.42$ \\
\hline
\end{tabular}

Table 4: Evolution process of $\mathrm{CHCP}$ antenna with $\mathrm{W}_{6}$

\begin{tabular}{|c|c|c|}
\hline S.no & $\mathbf{W}_{\mathbf{6}}$ & Reflection coefficient(dB) \\
\hline 1 & 0.4 & $-22.58,-14.09$ \\
\hline 2 & 0.3 & $-18.40,-15.86,-12.59$ \\
\hline 3 & 0.2 & $-21.425,-34.01,-11.96$ \\
\hline 4 & 0.1 & $-30.56,-18.68$ \\
\hline
\end{tabular}

The Figure 6 represents the radiation patterns for proposed antenna. Now, at frequency of $4.2 \mathrm{GHz}$ the antenna radiates maximum at $130^{\circ}$ (E-Plane) and $235^{\circ}$ (H-Plane), at resonant frequency $7.2 \mathrm{GHz}$ major radiation is at $335^{\circ}$ (E-Plane) and $85^{\circ}$ (H-Plane), for operating frequency $10.42 \mathrm{GHz}$ maximum radiation at $85^{\circ}$ (E-Plane) and $300^{\circ}$ (H-Plane).

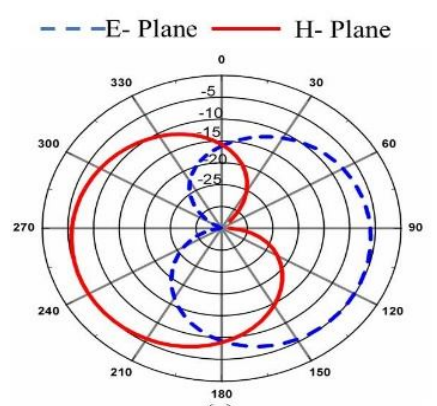

(a)

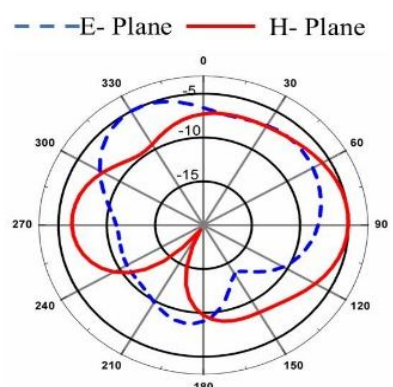

(b)

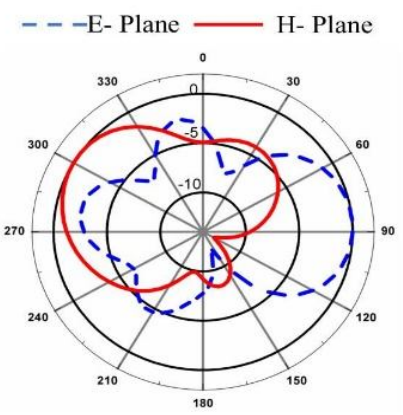

(c)

Figure 6: Proposed antenna directional patterns (a) $4.2 \mathrm{GHz}$ (b) $7.2 \mathrm{GHz}$ (c) $10.45 \mathrm{GHz}$
Below, Figure 7 presents 3D-gain plots proposed microstrip antenna at three operating frequencies $7.2 \mathrm{GHz}, 10.42 \mathrm{GHz}$ are $-7.5 \mathrm{~dB},-6 \mathrm{~dB}$ respectively and the negative gain is due to the lossy tissue surrounding the CHCP microstrip antenna.
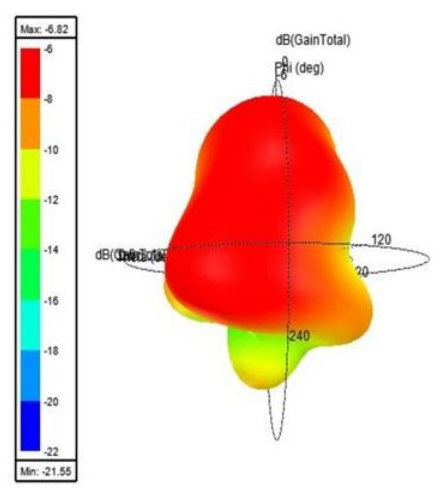

(a)

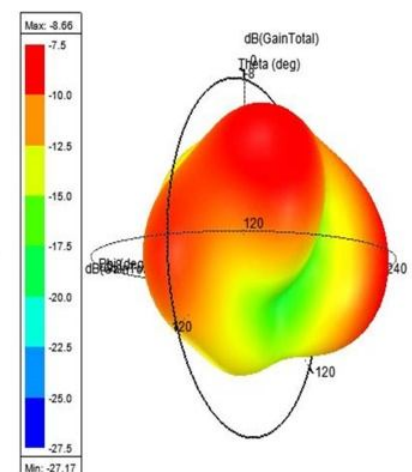

(b)
Figure 7: Proposed antenna 3D-Gain plots (a) $7.2 \mathrm{GHz}$ (b) $10.42 \mathrm{GHz}$

The following Figure 8 shows the current distribution on surface of the proposed antenna substrate at frequencies $4.2 \mathrm{GHz}, 7.2 \mathrm{GHz}, 10.42 \mathrm{GHz}$ along with current density meter for each operating frequency

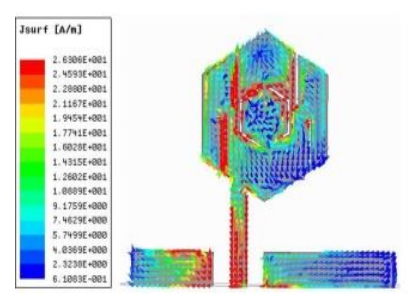

(a)
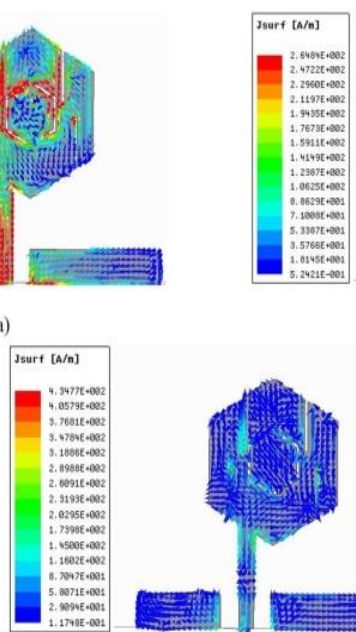

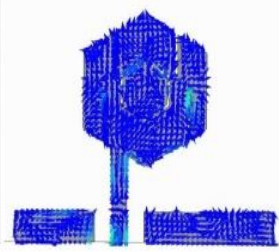

(b)

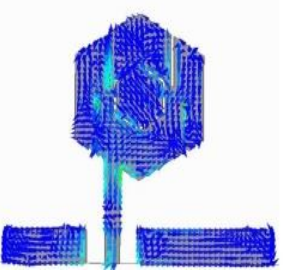

(c)

Figure 8: Proposed microstrip antenna current distribution at (a) $4.2 \mathrm{GHz}$ (b) $7.2 \mathrm{GHz}$ (c) $10.42 \mathrm{GHz}$

\subsection{Three-layer tissue analysis:}

When the proposed antenna is tested on single layer which is skin, the frequency of operation of antenna remains the same as in free space.

The antenna is further tested in a 3-layered model consists of skin and muscle on top and bottom having, fat layer in between them. The proposed antenna exhibited good reflection coefficient with $<-15 \mathrm{~dB}$, and when it is tested in the three-layer model, it resonates for the lower band of UWB. The frequency of operation is also the same; this process proves that the CHCP is best suited for on-body applications. 
In Figure 9 the gain been observed at different frequencies the pattern showed a directional gain which is best for the body which might reduce its effect of SAR and radiation. The SAR values for both simulating platforms are the same, which shows the CHCP antenna is suitable for on-body applications.

The specific absorption rate value is $(1.51 \mathrm{~W} / \mathrm{Kg})$ observed at frequency of $4.2 \mathrm{GHz}$ and $(1.516 \mathrm{~W} / \mathrm{Kg})$ for $7.2 \mathrm{GHz}$ and $(1.01$ $\mathrm{W} / \mathrm{Kg}$ ) for $10.42 \mathrm{GHz}$. So, the designed CHCP antenna is preferable for the on- body applications.

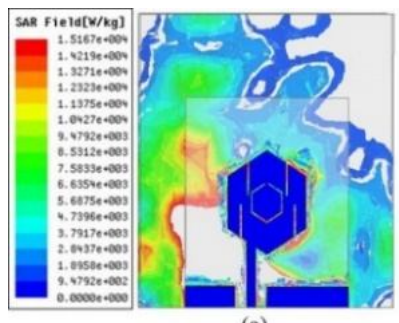

(a)

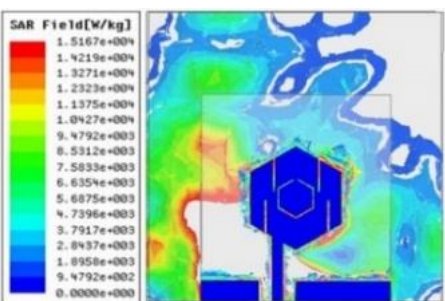

(b)

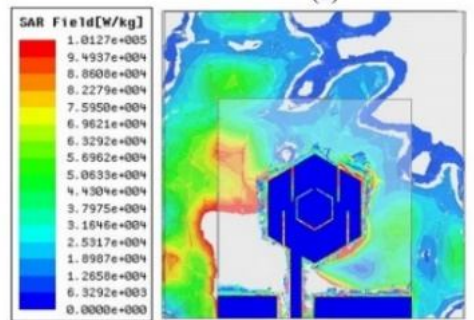

(c)
Figure 9: Proposed antenna SAR value for Single layer CHCP (a) $4.2 \mathrm{GHz}$ (b) $7.2 \mathrm{GHz}$ (c) $10.42 \mathrm{GHz}$

The antenna is simulated on the three-layer tissue with skin having a thickness of $2 \mathrm{~mm}$, fat layer having thickness $1 \mathrm{~mm}$, and a muscle layer with thickness $9 \mathrm{~mm}$.

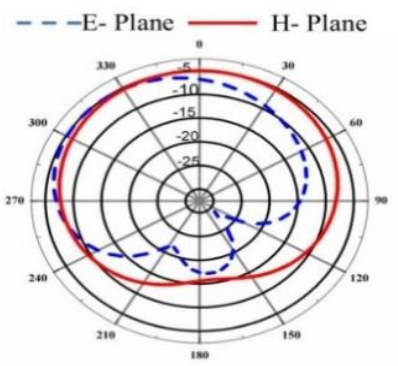

(a)

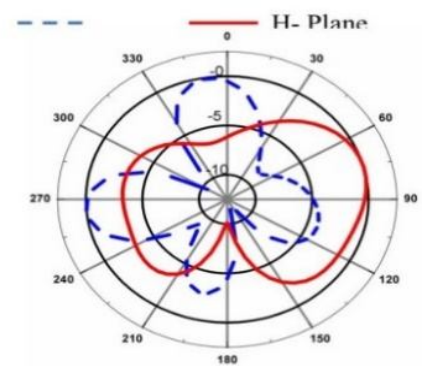

(b)
--- E- Plane - H- Plane

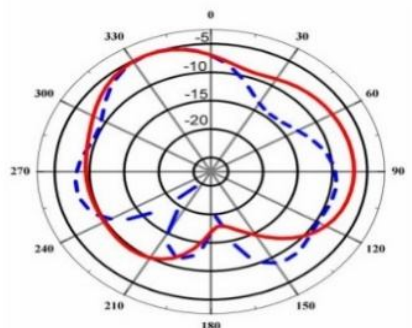

(c)

Figure 10: Proposed antenna directional patterns for 3-layer model (a) $3.84 \mathrm{GHz}$ (b) $6.15 \mathrm{GHz}$ (c) $9.65 \mathrm{GHz}$
The directional pattern of three-layer model is represented in above Figure 10 . At $3.84 \mathrm{GHz}$ the antenna radiates maximum in $313^{\circ}$ (E-Plane) and $0^{\circ}$ (H-Plane), $6.15 \mathrm{GHz}$ major radiation is at $265^{\circ}$ (E-Plane) and $75^{\circ}$ (H-Plane), for $9.61 \mathrm{GHz}$ the maximum radiation is at $340^{\circ}$ (E-Plane) and $335^{\circ}$ (H-Plane).

The Figure 11 shows the gain observed for the three-layer antenna model at operating frequencies of $3.84 \mathrm{GHz}, 6.15$ $\mathrm{GHz}, 9.65 \mathrm{GHz}$ are $-5 \mathrm{~dB},-15 \mathrm{~dB},-10 \mathrm{~dB}$ respectively and the negative gain is due to the lossy tissue surrounding the $\mathrm{CHCP}$ antenna.

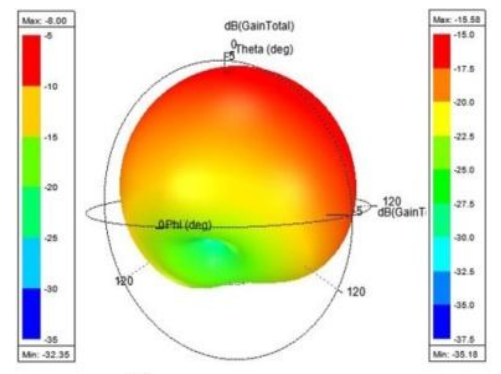

(a)

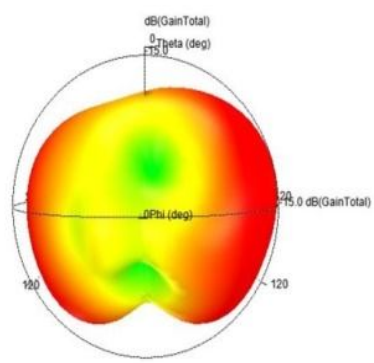

(b)
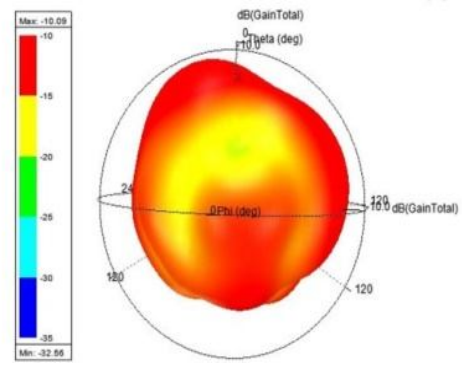

(c)

Figure 11: Proposed antenna 3D-Gain plots for 3-layer model at (a) $3.84 \mathrm{GHz}$ (b) $6.15 \mathrm{GHz}$ (c) $9.61 \mathrm{GHz}$

The specific absorption rate (SAR) value is standard for antennas which are used in on body applications. According to those standards (IEEE C95.1-2005) the SAR value shouldn't exceed more than $(1.6 \mathrm{~W} / \mathrm{Kg})$.

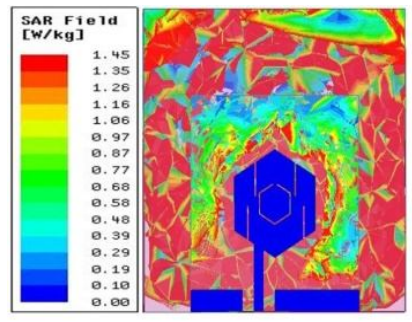

(a)

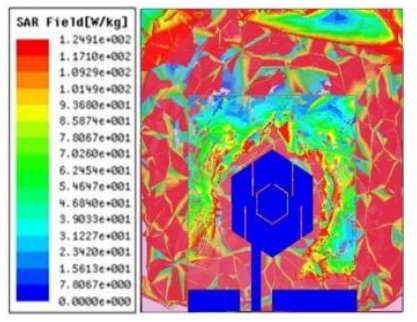

(b)

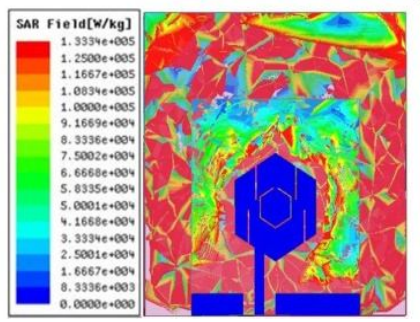

(c)

Figure 12: The SAR plot of the three-layer model in HFSS 19.0 at (a) $3.84 \mathrm{GHz}$ (b) $6.15 \mathrm{GHz}$ (c) $9.61 \mathrm{GHz}$ 
Above, Figure $12 \mathrm{SAR}$ of $(1.45 \mathrm{~W} / \mathrm{Kg})$ is observed for resonant frequency of $3.84 \mathrm{GHz}$ and $(1.24 \mathrm{~W} / \mathrm{Kg})$ for $6.15 \mathrm{GHz}$ and $(1.33 \mathrm{~W} / \mathrm{Kg})$ for $9.61 \mathrm{GHz}$. So the designed patch antenna is preferable for the on-body applications.

The below Figure 13 represents the reflection coefficient comparison for single layer model and three-layer model as the antenna has placed on the three-layer tissue there is shift in frequency and reflection coefficient that has been presented.

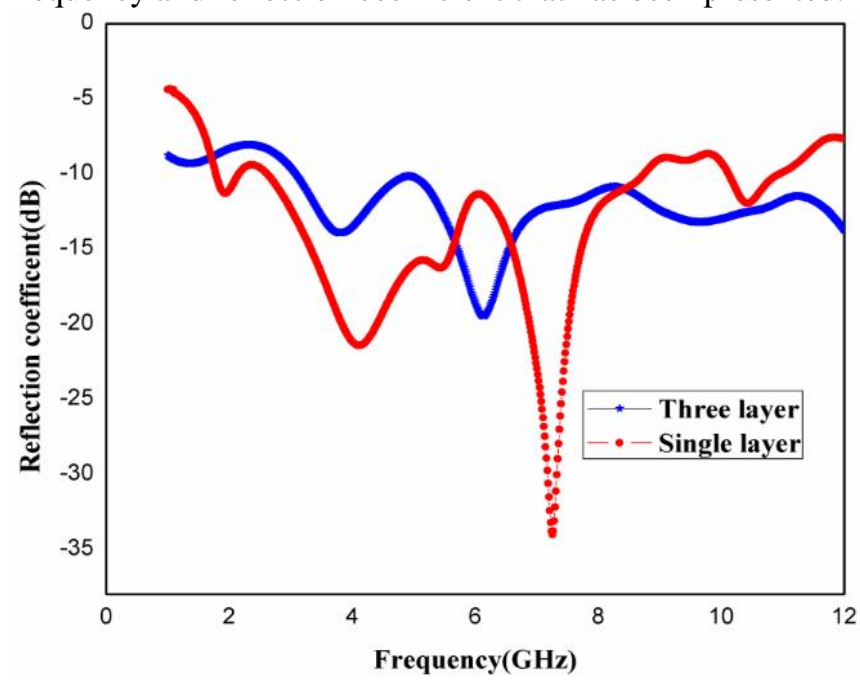

Figure 13: Proposed antenna $S_{11}$ comparison of single layer and three-layer tissues.

\section{CONCLUSION}

In this work, the proposed antenna design and analysis has been carried out by using Ansys HFSS_19.0 simulator software with total size of $\left(20 \times 18 \times 0.08 \mathrm{~mm}^{3}\right)$ which is very compact CPW-Fed hexagonal shaped circular patch antenna along with slits which has CSRR structure is presented. The prototype microstrip antenna resonates at three operating frequencies they are $4.1 \mathrm{GHz}, 7.2 \mathrm{GHz}$, and $10.42 \mathrm{GHz}$. The proposed microstrip antenna covers UWB. Therefore, parametric analysis and Evolution process are studied.

Finally, the proposed antenna exhibits better gain and reflection coefficient for the entire band of operation. The current distribution and SAR of the antenna are satisfied. The specific absorption rate (SAR) of the antenna is also plotted for three-layer model and the SAR value for the prototype microstrip antenna is within (IEEE C95.1-2005) standards. So, the antenna is preferable for on-body applications.

\section{REFERENCES}

1. A. W. Astrin, H. B. Li, and R. Kohno, Standardization for body area networks, IEICE Trans. Commun., vol. E92-B, no. 2, pp. 366-372, Feb. 2009. https://doi.org/10.1587/transcom.E92.B.366

2. X. Li, M. Jalivand, Y. Sit, and T. Zwick, A compact double-layer on-body matched bowtie antenna for medical diagnostics, IEEE Trans. Antennas Propag., vol.62, no.4, pp.1808-1816, Apr.2014.
3. C. H. Kang, S. J. Wu, and J.H. Tarng, A novel folded UWB antenna for wireless body area network, IEEE Trans. Antennas Propag., vol. 60, no. 2, pp. 1139-1142, Feb. 2012.

4. N. Chahat et al., A compact UWB antenna for on-body applications, IEEE Trans. Antennas Propag., vol. 59, no. 4, pp. 1123-1131, Apr. 2011.

5. T.See and Z. N. Chen, Experimental characterization of UWB antennas for on-body communications, IEEE Trans. Antennas Propag., vol. 57, no. 4, pp. 866-874, Apr. 2009.

6. Kumar V, Gupta B, On-body measurements of SS-UWB patch antenna for WBAN applications, Int J Electron Commun (AEÜ) (2016). https://doi.org/10.1016/j.aeue.2016.02.003

7. Z. N. Chen, A. Cai, T. S. P. See, and M. Y. W. Chia, Small planar UWB antennas in the proximity of the human head, IEEE Trans. Microw. Theory Tech., vol. 54, no. 4, pp. 1846-1857, Jun. 2006.

8. Khaleel, H. R., H. M. Al-Rizzo, and D. G. Rucker, Compact polyimide-based antennas for flexible displays, Journal of Display Technology, Vol. 8, 91-97, 2012.

9. B. Hazarika, B. Basu, J. Kumar, A Multi-Layered Dual-Band On-Body Conformal Integrated Antenna for WBAN Communication, International Journal of Electronics and Communications (2018), doi:

10. Q. Wang, T. Tayamachi, I. Kimura, and J. Wang, An on-body channel model for UWB body area communications for various postures, IEEE Trans. Antennas Propag., vol. 57, no. 4, pp. 991-998, Apr. 2009

11. M. Zhadobov, N. Chahat, R. Sauleau, C. Le Quément, and Y. Le Dréan, Millimeter-wave interactions with the human body: State of knowledge and recent advances, Int. J. Microw. Wireless Technol., vol. 3, no. 2, pp. 237-247, 2011

12. Vyas, K., Sanyal, G., Sharma, A. K., \& Singhal, P. K. (2014). Gain enhancement over a wideband in CPW-fed compact circular patch antenna. International Journal of Microwave and Wireless Technologies, 6(5), 497-503. https://doi.org/10.1017/S1759078713001037

13. Ketavath Kumar Naik and Dattatreya Gopi, Flexible CPW-fed split-triangular shaped patch antenna for WiMAX applications, Prog. Electromagn. Res M, vol. 70, pp. 157-166, Jul. 2018.

14. N. Siddaiah, B. Sri Keerthana Reddy, B. Manoj Kumar, K. Raja Sekhar, G. Venkata Ganesh, Performance Analysis Of Low Pullin Voltage RF MEMS Switch For Reconfigurable Antenna Applications, International Journal of Emerging Trends in Engineering Research, Vol. 7, pp. 670 - 676, Nov. 2019.

15. J. Y. Chiou,J.Y.Sze and K.L.Wong, A broad-band CPW-Fed strip loaded square slot antenna, IEEE Trans.Antennas and Propag vol.51,no.4.pp.719-721,April 2003.

16. H.-W. Liu, C.-H. Ku, and C.-F. Yang, Novel CPW-fed planar monopole antenna for WiMAX/WLAN applications, IEEE Antennas Wireless Propag. Lett., vol. 9, pp. 240-243, 2010. 
17. Elsheakh, Dalia M., and Esmat A. Abdullah. Ultra-wide-bandwidth (UWB) microstrip monopole antenna using split ring resonator (SRR) structure, International Journal of Microwave and Wireless Technologies 10.1 (2018): 123-132.

18. X. Sun, G. Zeng, H.-C. Yang, and Y. Li, A compact quad band CPW-fed slot antenna for M-WiMAX/WLAN applications, IEEE Antennas Wireless Propag. Lett., vol. 11, pp. 395-398, 2012

19. S.M. Deng and H.H.kan Analysis of CPW-fed triangle patch antennas, IEEE Trans.Antennas and Propag., vol. 3 ,pp. 398-401,2001

20. V.G. Veselago, The electrodynamics of substances with simultaneously negative values of $E$ and $I$, Sov Phys Usp 10 (1968), 509-514.

21. J. D. Baena, J. Bonache, F. Martin, R.M. Sillero, F.Falcone, Equivalent-circuit models for split-ring resonators and complementary split-ring resonators coupled to planar transmission lines, IEEE Trans Microwave Theory Tech 53 (2005), 1451-1461

22. J.-R. Huu and J.-S. Li, Compact microstrip antennas using CSRR structure ground olane, Microwave Opt Technol Lett 56 (2014), 117-120.

https://doi.org/10.1002/mop.28023 